LBL- -32729

DE93 001586

\title{
Progress Report on Modeling Studies: \\ Natural State Conditions and Exploitation of the Dachny Geothermal Reservoir, Mutnovsky Hydrothermal System, Kamchatka, Russia
}

\author{
A. V. Kiryukhin \\ Visiting Scientist* \\ Earth Sciences Division \\ Lawrence Berkeley Laboratory \\ University of California \\ Berkeley, California 94720 \\ "Permanent Address: \\ Institute of Volcanology \\ Petropavlovsk-Kamchatsky \\ 683006, Russia
}

July 1992

This work was supported by the Assistant Secretary for Renewable Energy, Geothermal Division, of the U.S. Department of Energy under Contract No. DE-AC03-76SF00098.

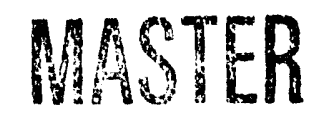




\title{
PROGRESS REPORT ON MODELING STUDIES: NATURAL STATE CONDITIONS AND EXPLOITATION OF THE DACHNY GEOTHERMAL RESERVOIR, MUTNOVSKY HYDROTHERMAL SYSTEM, KAMCHATKA, RUSSIA
}

\author{
A.V. Kiryukhin* \\ Institute of Volcanology, Petropavlovsk-Kamchatsky, 683006, Russia
}

\begin{abstract}
The spatial distribution of pre-exploitation conditions (e.g. temperature and pressure distributions, liquid and vapor saturations, circulation characteristics of high-temperature fluids) in the Dachny site of the Mutnovsky hydrothemal system, obtained earlier using a 3-D mapping method (Kiryukhin et al, 1991), are revised on the basis of natural state simulations performed with the computer code TOUGH2 (Pruess, 1991). A 3-D model of the natural state conditions at the Dachny site was developed. The fine-tuning of the model has been achieved by comparing model results to the observations made in geothermal wells $1,24,01,016$ and 26 during flow tests conducted during 1983-88. The behavior of these five wells in response to two exploitation scenarios, one with no reinjection, the other with $100 \mathrm{~kg} / \mathrm{s}$ of liquid injection into well 027 , was also computed.
\end{abstract}

\section{INTRODUCTION}

The Mutnovsky geothermal field is located $75 \mathrm{~km}$ south of the city of PetropavlovskKamchatsky, close to the northern foothills of the Mutnovsky volcano, at an elevation of 800 to 900 meters above sea level (masl). The results of geothermal and geochemical investigations of this field were presented by Vakin et al. $(1976 ; 1986)$. Later on, a 3-D mapping of the lithologic units, temperature and pressure fields and a natural-state (pre-exploitation) model of the fluid flow within the Dachny site were completed (Kiryukhin et al., 1991; Kiryukhin, 1992).

It is felt that the results of these studies should be checked against those of a distributed-parameter numerical model. In addition, even though by 1990 sufficient steam reserves to generate $78 \mathrm{MWe}$ have been confirmed (Perveev, S., pers. com.), it is important to compute numerically the estimated long-term generating capacity of the field. For these purposes the computer code TOUGH2 (Pruess, 1991) with the addition of a new subroutine to simulate two-phase well discharge (Kiryukhin and Sugrobov, 1987), was used.

\section{DESCRIPTION OF INPUT DATA TO MODEL THE DACHNY RESERVOIR}

The underlying model to compute the natural state of the Dachny site was based on results of the 3-D mapping of the lithology, temperature and pressure fields, and chemistry and tracer test data, as well as on simple lumped-parameter analysis of flow test data. This model, shown schematically in Fig. 1, corresponds to a parallelepiped having prescribed temperature, pressure

\footnotetext{
* The draft manuscript supplied by A.V. Kiryukhin was edited by M. Lippmann and K. Pruess.
} 
and petrophysical distributions within, and inflows and outflows along its boundaries (Kiryukhin, et al., 1991; Kiryukhin, 1992).

The main purpose of this part of the study is to check the model of the Dachny reservoir from a physical point of view (e.g. mass and energy conservation) and to assure that during a long time period $\left(\mathrm{N}^{*} 100\right.$ years) the model is able to maintain stable conditions (i.e. without undergoing significant changes in pressures, temperatures and saturations) and compute fluid and heat outputs that agree with measured values. The input parameters to the model were adjusted accordingly to improve the match between calculated and observed values.

\section{Computational Grid}

A regular 3-D cartesian grid was used to model heat and mass transfer within the system (Fig. 2). The grid consists of five layers, each layer having eighty $1.25 \times 10^{8} \mathrm{~m}^{3}$ cubic elements. The center of the top-layer elements is at 750 masl. The name of the elements (AIJK) indicates the layer number (I), the number in the $y$ direction $(J)$ and the number in the $x$ direction $(K)$. The dimensions of the model correspond to the known volume of the Dachny hydrothermal reservoir and includes all of its main features (Fig. 1).

\section{Initial Temperature and Pressure Distribution}

To determine the initial temperature and pressure distribution in layers 2-5, a 3-D mapping procedure based on geothermal well logging was used. The input data were updated as of August 1990 (Perveev, S., pers. com.). Temperatures were slightly modified to agree with Na-K geothermometer data of flowing wells $(1,01,24,013$ and 037$)$.

Temperatures and pressures were calculated for the center of each block (Fig. 2). Small adjustments were made to represent a two-phase zone in blocks A242, A243, A251, A252, A253, A263, where steam saturation was set to 0.5 , and in blocks A323, A333, A343, A353, A363, A324, A334, A325, A335, A345, A355, A365, where steam saturation was set to 0.03 . These assignments were later corrected during the natural-state runs. The first layer was used to represent conductive heat losses; its temperature was set to $15^{\circ} \mathrm{C}$ and its pressure to $0.1 \mathrm{MPa}$ except for a small permeable block (A142), where natural steam discharge was simulated.

\section{Rock Properties}

The petrophysical parameters were assigned to the model elements as appropriate for the main lithologic units identified within the Dachny reservoir (see Table 1; Yanovsky, 1989; Delemen, I.F., pers. com.),

The distribution of these units within the model grid was obtained by using a 3-D mapping procedure (Kiryukhin et al., 1991). Fracture porosity in all elements was set to 0.5 . Other petrophysical parameters were assigned layer by layer, as follows, Unit (1): Layers 1, 2; Unit (2): Layer 3; Unit (3): Layer 4; Unit (4): Layer 5. 
Table 1. Petrophysical parameters for the Dachny Reservoir

\begin{tabular}{|l|c|c|c|c|}
\hline & & & & \\
\hline $\begin{array}{l}\text { (1) Quatemary ignimbrites, } \\
\text { Pliocene lavas \& hyolitic } \\
\text { tuffs }\end{array}$ & 2100 & 0.2 & 2.05 & 1000 \\
\hline (2) Miocene sandstones & 2300 & 0.08 & 2.1 & 1000 \\
\hline (3) Intrusive contact zone & 2400 & 0.03 & 2.1 & 1000 \\
\hline (4) Diorites & 2700 & 0.02 & 2.1 & 1000 \\
\hline
\end{tabular}

\section{Permeability Distribution}

For modeling natural-state (quasi-steady) conditions a single porosity approach was used. The permeability-thickness data were obtained from the interpretation of cold water injection falloff tests (Benson and Bodvarsson, 1986; Perveev, S., pers. com.) The permeabilitythicknesses assigned to the vertical intervals $(-1500,-1000),(-1000,-500),(-500,0)$, and $(0$, +500 ) masl were consistent with Layers 2-5 of the 3-D model. To Layer 1 a low permeability $(\mathrm{k}=$ $0.001 \mathrm{mD}$ ) was assigned, with the exception of natural discharge element A142 (see below). For each of the other layers the following estimated average permeabilit:es were used: Layer 2, 15 $\mathrm{mD}$ (based on 7 falloff tests); Layer 3, $6 \mathrm{mD}$ (based on 9 falloff tests); Layer 4, $5 \mathrm{mD}$ (based on 16 falloff tests); Layer 5, $3 \mathrm{mD}$ (based on 5 falloff tests).

A more permeable domain identified as "lay 6", is assumedl to coincide with the Paryashy fault, a natural steam discharge area and steam-dominated reservoir. This domain includes blocks: A142, A242, A243, A253, A263, A342, A333, A343, A353, A363, A442, A443, A453, A463, A542, A543, A553 and A563.

\section{Boundary Conditions}

The 3-D mapping of the geological structure and thermodynamic daia, and a geochemical study of the produced fluids, indicated that two upflow zones and one relatively cool downflow zone exist in the Dachny site. The total rate of upflow is estimated at $228 \mathrm{~kg} / \mathrm{s}$, with an enthalpy of $1390 \mathrm{~kJ} / \mathrm{kg}$; the total estimated downflow rate is $185 \mathrm{~kg} / \mathrm{s}$ (Kiryukhin, 1992).

Based on these data, sources and sinks were assumed to exist at the bottom layer (Layer 5). Sources were assigned to 12 blocks associated with high-temperature anomalies thought to correspond to the upflow regions (see Fig. 2): A522, A532, A542, A523, A533, A543, A553, A524, A534, A545, A555 and A565. Appropriate mass rate and enthalpy were specified in each block so that, as a first approximation, the total mass upflow was $228 \mathrm{~kg} / \mathrm{s}$.

Sinks were assigned to the following six blocks considered to be related to the downflow region: A563, A573, A544, A554, A564 and A574. A mass flow rate of $15 \mathrm{~kg} / \mathrm{s}$ was specified in 
each of these blocks, so that total downflow is about half of the suggested $185 \mathrm{~kg} / \mathrm{s}$, because discharge is also allowed in the comers of the bottom layer by way of inactive elements. To maintain realistic pressures, corresponding to the surrounding hydrogeological system, four inactive elements in the corners of the bottom layer were included in the model: (A511, A5A1, A518 and A5A8). These elements remain at initial (constant) pressures and temperatures corresponding to the "outside" area. Natural steam output was simulated with the inactive element A142 located in the upper layer, which was maintained at a fixed temperature and pressure of $110^{\circ} \mathrm{C}$ and $0.1 \mathrm{MPa}$, respectively.

\section{MODELING THE NATURAL (QUASI-STEADY) STATE OF THE DACHNY RESERVOIR}

\section{Key Elements For Model Calibration}

The computed thermodynamic conditions of some elements were selected as key points to calibrate the model (see Table 2).

Table 2. Dachny model calibration.

\begin{tabular}{|c|c|c|c|}
\hline Elemen! & Well & Temperature ( & Phase Saturation \\
\hline A253 & 016 & 228 & 2-Phase \\
\hline A263 & 26 & 236 & 2-Phase \\
\hline A333 & 01 & 275 & 2-Phase \\
\hline A354 & 1 & 276 & 2-Phase \\
\hline A364 & 24 & 265 & $6.2 \mathrm{MPa}$ \\
\hline A455 & 013 & 305 & $10.0 \mathrm{MPa}$ \\
\hline A467 & 037 & 284 & $9.8 \mathrm{MPa}$ \\
\hline
\end{tabular}

These key elements are associated with areas where flow tests were performed and where there is pressure-temperature log data.

In addition to these elements, the steam flow between elements A242 and A142 was considered as an indication of correctly modeling the natural discharge at the Dachny site. The thermal discharge has been estimated to be from 38 to $74 \mathrm{MW}$ (Vakin et al., 1976; 1986) corresponding to a steam flow rate of 13 to $26 \mathrm{~kg} / \mathrm{s}$. We emphasize that approximately $72 \%$ of the heat discharged at Dachny is believed to be associated with heat losses from hot ground and distributed fumaroles, with an uncertainty of up to 25\% (Allis, 1981). It is considered that previous estimates of natural-state thermal output at Dachny might be excessive since a too large heat transfer coefficient $\left(1.45 \mathrm{kcal} / \mathrm{s}-\mathrm{cm}^{2}\right.$ or $\left.6 \mathrm{~kW} / \mathrm{m}^{2}\right)$ for hot ground with temperature above $20^{\circ} \mathrm{C}$ at a depth of $50 \mathrm{~cm}$ was assumed by Vakin et al. (1976). According to Allis (1981) this coefficient should be $0.05 \mathrm{~kW} / \mathrm{m}^{2}$ for hot ground with temperatures of $25-80^{\circ} \mathrm{C}$ at $15 \mathrm{~cm}$ depth. 


\section{Adjustment of Boundary Conditions}

Initial computer runs were made assuming no inactive elements in the bottom layer. These gave unreasonable pressure increases in almost all blocks of the model (from 1.4 to $3.5 \mathrm{MPa}$ ) and collapse of the two-phase zone in a number of key blocks, unless the upflow was decreased first to $114 \mathrm{~kg} / \mathrm{s}$ and then to $30 \mathrm{~kg} / \mathrm{s}$, and the permeability in the special domain "lay 6" increased from 30 to $90 \mathrm{mD}$. Computed natural-state discharge in element A142 was 6.2 to $27.9 \mathrm{~kg} / \mathrm{s}$, but with an unrealistic low steam fraction $(0.2$ to $1.4 \mathrm{~kg} / \mathrm{s})$. These results show the need to include some constraints to maintain hydrodynamic pressure control throughout the model. This was the reason for adding to the grid the four inactive elements at the comers of the bottom layer.

A simulation with bottom inactive elements, and natural upflow recharge of $228 \mathrm{~kg} / \mathrm{s}$ results in too high reservoir pressures (by about 0.7 to $0.8 \mathrm{MPa}$ ). On the other hand, a recharge of 114 $\mathrm{kg} / \mathrm{s}$ gives too low pressures (a deficiency of 0.6 to $0.7 \mathrm{MPa}$ ). It was found that an intermediate upflow value of $168 \mathrm{~kg} / \mathrm{s}$ maintains the most appropriate pressures in the key elements.

\section{Influence of Permeability and Relative Permeability}

Corey relative permeability curves were used in the computer runs discussed above. The most important effect of the relative permeabilities is on the natural steam output, which remains too low $(1.4 \mathrm{~kg} / \mathrm{s})$ when the Corey curves are used in the computations. Changing to Grant's (1977) relative permeability curves, which are more appropriate for fractured media, results in an increase in steam output in $\mathrm{A} 142$ (up to $5.2 \mathrm{~kg} / \mathrm{s}$ ).

Increasing the permeability up to $150 \mathrm{mD}$ in the special domain "lay 6", which simulates the permeable zone below the natural discharge area (element A142), one obtains a stable steam output in $\mathrm{A} 142$ of $7.4 \mathrm{~kg} / \mathrm{s}$, or $21 \mathrm{MW}$. Pressures and temperatures in key elements of the mesh were quite reasonable. Further increasing the "lay 6" permeability to $500 \mathrm{mD}$ did not give a significant increase in steam output in A142; it reached a quasi-steady value of $7.9 \mathrm{~kg} / \mathrm{s}$.

In subsequent calculations a permeability of $150 \mathrm{mD}$ was used since it allowed the most appropriate equilibrium between reservoir pressures and temperatures and the steam output in A142 (Vakin et al., 1976; 1986).

The appearance of an unrealistic extension of the two-phase zone in Layer 2 and temperatures in Layer 3 during quasi-steady modeling was avoided by locating permeability restrictions in the north-west and south-east regions of these two layers.

\section{Final Model of the Natural State of Dachny Reservoir}

On the basis of the calibration studies discussed above the following improvements in the input data were made:

1. Only Grant's (1977) relative permeabilities were used.

2. A more permeable domain "lay 6" was assumed in the model, having a permeability of $150 \mathrm{mD}$.

3. The total upflow was assumed to be $165 \mathrm{~kg} / \mathrm{s}$. 
4. Layer 2 was assigned low permeabilities except for blocks associated with the steamdominated reservoir.

5. Layer 3 was assigned low permeabilities in NW and SE regions of the reservoir.

By adjusting the model, a reasonable comparison between calculated and observation-derived input values of pressure, temperature and phase conditions was obtained in the key elements used for validating the model. The values for a sufficiently long running time are given in Table 3:

Table 3. Calibration of revised Dachny model.

\begin{tabular}{|c|c|c|c|c|c|c|c|c|c|}
\hline \multirow{3}{*}{ Element } & \multirow{2}{*}{\multicolumn{3}{|c|}{ Input Data }} & \multicolumn{6}{|c|}{ Compuled Values } \\
\hline & & & & \multicolumn{2}{|c|}{ t $=301$ years } & \multicolumn{2}{|c|}{ I=356 years : } & \multicolumn{2}{|c|}{$t=20,648$ years } \\
\hline & Well \# & T $(9 \mathrm{C})$ & Ph/PII) & $\mathrm{T}\left({ }^{\circ} \mathrm{C}\right)$ & $\mathrm{Ph} / \mathrm{P}^{(1)}$ & T $(9 \mathrm{C})$ & $\mathrm{Ph} / \mathrm{P}^{(I)}$ & T (9) & $\mathbf{P h} / \mathbf{P}(1)$ \\
\hline A253 & 016 & 228 & 2-Ph. & 223 & 0.66 & 223 & 0.66 & 224 & 0.59 \\
\hline A263 & 26 & 236 & 2-Ph. & 223 & 0.64 & 223 & 0.63 & 225 & 0.58 \\
\hline A.333 & 01 & 275 & 2-Ph. & 278 & 0.06 & 278 & 0.05 & 279 & 0.06 \\
\hline A354 & 1 & 276 & 2-Ph. & 266 & $6.1 \mathrm{MPa}$ & 268 & 6.1 MPa & 276 & $6.3 \mathrm{MPa}$ \\
\hline A364 & 24 & 265 & $6.2 \mathrm{MPa}$ & 266 & $6.0 \mathrm{MPa}$ & 268 & $6.0 \mathrm{MPa}$ & 276 & 6.2 MPa \\
\hline A455 & 013 & 305 & $10.0 \mathrm{MPa}$ & 303 & $9.7 \mathrm{MPa}$ & 303 & $9.7 \mathrm{MPa}$ & 305 & $9.8 \mathrm{MPa}$ \\
\hline A467 & 037 & 284 & $9.8 \mathrm{MPa}$ & 288 & $9.5 \mathrm{MPa}$ & 289 & 9.5 MPa & 300 & 9.7 MPa \\
\hline
\end{tabular}

(1) Phase Saturation (values less than 1) or Pressure (in MPa)

Figs. 3 and 4 show a comparison between observed and simulated spatial distributions of temperatures and pressures in Layers 2 to 4 . A reasonably good match is found for temperatures in Layers 2 and 4 . Although the temperatures computed for Layer 3 are somewhat high (by about 5 to $10^{\circ} \mathrm{C}$ ), they are reasonable because of significant cooling of this layer during drilling (most of the production zones were found at these depths, and most of the wells showed significant drilling mud losses).

Observed and simulated pressures are generally in good agreement, however some specific features are different. For example, a low pressure anomaly in the region of wells 01-24 was not observed in the model (Layers 3 and 4). This anomaly can be explained by the 1983-88 flow tests that produced some disturbances within the reservoir. Note that for the 3-D temperature-pressure reconstruction data up to 1990 were used, because there was not enough pre-1983 data available.

Computed steam output in $\mathrm{A} 142$ was $4.5 \mathrm{~kg} / \mathrm{s}$ (or $13.0 \mathrm{MW}$ ). If $8 \mathrm{MW}$ of conduction losses are added, the total calculated thermal discharge in that area will be $21 \mathrm{MW}$. Although it is only 28-55\% of the total output estimated for the Dachny site (Vakin et al., 1976; 1986), the results of the model seem to be reasonable considering the poor heat transfer coefficient values used by Vakin et al. (see above). On the other hand, it is important to note that, although a large quasi- 
stationary steam rate is "prohibited" in the model, during the first 100-200 years of modeling time one could obtain steam rates of up to $10-17 \mathrm{~kg} / \mathrm{s}$ in A142; see Fig. 5. This behavior is most likely an artefact of the model, reflecting lack of equilibrium in the postulated initial state.

The improved natural-state model of the Dachny site, Mutnovsky geothermal field, is shown in Fig. 6.

\section{MOdeling OF VARIOUS EXPLOITATION REgIMES FOR THE DACHNY SITE}

\section{Modeling Geothermal Wells (Sinks)}

The usual method of simulating a geothermal well as a sink/source of constant rate or constant bottom-hole pressure is not appropriate for studying the Dachny site, because the rate equation is non-linear:

$$
Q=P I *\left[P_{r}-P_{b}(W H P, Q, h, d)\right]
$$

where $\mathrm{Q}$ is the well mass rate, $\mathrm{PI}$ the productivity index, $\mathrm{P}_{\mathrm{r}}$ the reservoir pressure, $\mathrm{P}_{\mathrm{b}}$ the bottomhole pressure which depends on $Q$, well-head pressure (WHP), flowing enthalpy (h), and $d, a$ function of well casing design. There are a number of methods to obtain bottom-hole pressures (e.g. Droznin, 1980; Aunzo et al., 1991).

To solve Eq. (1) for each of the producing wells in the model a special subroutine DEBIT (Kiryukhin and Sugrobov, 1987) was used. This subroutine added to the code TOUGH2 (Pruess, 1991), computes at each time step and for any grid block containing a geothermal well, new values of $\mathrm{Q}$. In this procedure $\mathrm{PI}, \mathrm{Pr}_{\mathrm{r}}$ (reservoir pressure in the grid block containing the geothermal well), WHP, $h$, and $d$ are input data, and $Q$ is the unknown.

\section{FINE-TUNING The MOdel ON THE BaSis OF Flow TEST DATA}

Flow-tests were conducted during 1983-88 in wells 016, 26, 01, 014, 1, 24 and 013. Unfortunately only in late 1987 some of wells $(1,01,24)$ were equipped with James tanks for accurate measurement of discharge enthalpy. Therefore, one can only match well characteristics for the last period of observations. Wells 016 and 26 produce only steam so that the use of small calorimeters is appropriate to assess the enthalpy of their discharge. In some other wells $(014$, 013) discharge rates and enthalpies were not measured, thus in the model a constant discharge rate was assumed.

In the model, when the wells come on line, their discharge is computed using either subroutine DEBIT (wells 01, 1, 24, 016, 26) or a constant discharge is assumed (i.e. well 013: $35 \mathrm{~kg} / \mathrm{s}$; well $014: 8 \mathrm{~kg} / \mathrm{s})$.

Initial computer runs were made assuming a single-porosity approach for the reservoir. The results showed unreasonably low enthalpy values for the above-mentioned wells, indicating that a more effective heat extraction mechanism and a less effective mass transfer mechanism is occurring in the reservoir. That is, a double-porosity model is needed to simulate the reservoir behavior. 
Hence a fracture porosity of $2 \times 10^{-4}$ to $2 \times 10^{-5}$ and three fracture sets of $200 \mathrm{~m}$ spacing were assigned. The fractures were considered the main permeable zones of the model as opposed to the relatively impermeable matrix media ( $\mathrm{k}=$ microdarcies). The GMINC approach (Pruess, 1983) was used to develop the mesh for the double-porosity model.

A number of computer runs were made to calibrate the model (Fig. 7). In the first stage of calibration, PI was estimated on the basis of the final discharge and enthalpy of the wells during simulated flow tests. Then, the enthalpy-discharge calibration against well data was improved on the basis of the following principle: to achieve an increase in enthalpy one can (i) decrease the local permeability of the grid block containing a given well, (ii) decrease the permeabilities of adjacent blocks containing low-enthalpy fluids, or (iii) augment the permeabilities in the adjacent blocks containing high-enthalpy fluids. For a decrease in computed enthalpy one has to follow the opposice procedure. In particular, a specially effective method to manipulate enthalpies is to change the permeabilities of the underlying blocks, which usually contain colder fluids.

Another factor which may control enthalpies is the contact area between fractures and matrix (or the fracture spacing specified in GMINC). It is worthwhile to note that in this case the matrix permeability has a smaller impact on enthalpies; for example, decreasing the permeability from $7 \times 10^{-18}$ to $5 \times 10^{-19} \mathrm{~m}^{2}$ has no effect on enthalpy.

\section{Calibration of Individual Wells}

Well 1 (Element A354). The 1983-88 flow tests started with this well. At the first stage of calibration, PI was estimated as $30 \mathrm{~kg} / \mathrm{s}-\mathrm{MPa}$ on the basis of the final discharge-enthalpy of the well during the simulated flow tests. During the refinement of the enthalpy-discharge calibration the permeability in element A254 was increased to $0.2 \mathrm{mD}$, and in A355 to $150 \mathrm{mD}$.

Well 26 (Element A263). The calibration of this well was next since its test began after that of well 1. The same calibration procedures as in well 1 were followed. The best estimated value for PI was $300 \mathrm{~kg} / \mathrm{s}-\mathrm{MPa}$. During the next stage of enthalpy-discharge calibration the permeability of some elements in the model were modified. That is, the permeability of A163 (underlying block) was changed to $0.7 \mathrm{mD}$; that of A273, A274 and A262 (adjacent blocks to make production rate more stable) to $150 \mathrm{mD}$; that of $\mathrm{A} 353$ and $\mathrm{A} 363$ decreased to $6 \mathrm{mD}$ (to avoid significant influence on well 1); and that of the matrix in element A263 increased to $60 \mathrm{mD}$ (to better stabilize the well production rate).

Well 01 (Element A333). This is the third well that was added to the flow test. The most appropriate PI was $70 \mathrm{~kg} / \mathrm{s}-\mathrm{MPa}$. During the fine-tuning of the enthalpy-discharge, the permeability in A333 was decreased to $3.0 \mathrm{mD}$; that of the of underlying element A233 was increased to 0.1 $\mathrm{mD}$, and the contact area between fractures and matrix in A333 was increased 3.3 times.

Well 016 (Element A253). This is the fourth well added to the flow test. The most appropriate PI was $50 \mathrm{~kg} / \mathrm{s}-\mathrm{MPa}$. During the refinement of the calibration the following permeability changes were made: A153 (underlying block) $0.9 \mathrm{mD}$; A232, A242, A243 and A244 (adjacent elements of the second layer) $150 \mathrm{mD}$; and A253 (matrix permeability) $60 \mathrm{mD}$.

Wells 013 and 014 were "turned on" in the model after well 016. Because their enthalpies are not clearly known, these wells were simulated in the model as sinks having constant rates of 35 and $8 \mathrm{~kg} / \mathrm{s}$, respectively. 
Well 24 (Element A364). This is the last well added to the flow test. The appropriate PI was $100 \mathrm{~kg} / \mathrm{s}-\mathrm{MPa}$. For fine-tuning the match of the observed enthalpy-discharge characteristics of the wells, the following permeability modifications were made: in A264 (underlying block) changed to $0.1 \mathrm{mD}$; in $\mathrm{A} 364$ changed to $4 \mathrm{mD}$ and the fracture/matrix contact area was increased 4.7 times.

On the basis of these results some changes in the permeability distribution in the basic model of the Dachny site were made (Fig. 7). It is worthwhile to note that in the model the upper inflow to the flowing wells is $7 \mathrm{~kg} / \mathrm{s}$. The only way to agree with the measured tritium data (Kiryukhin et al., 1991) is to suggest that the initial tritium concentration in the reservoir was 2 T.U., and not 0 T.U. This would be the result of the significant cold water influxes to the reservoir during well drilling operations.

It is also very interesting to note that the model suggests a decrease in steam output in the discharge area (Element A142) during the flow test (Fig. 5b) and, as will be shown below, an increase of steam output during exploitation.

\section{MODELING OF DIFFERENT EXPLOITATION SCHEMES}

Modeling the behavior of wells 26, 016, 1, 01, 24, 013 and 014 during a 20-year exploitation period is very useful to predict the possible response of the reservoir during the operation of the proposed $70 \mathrm{MW}$ electric power plant. The study was performed using the previously improved natural-state model of the system to which was added well 037 having a constant rate of $30 \mathrm{~kg} / \mathrm{s}$. The temperature, pressure and saturation data measured at the end of the 1983-88 (55 monthlong) flow tests were assumed to be the initial conditions for the modeling study.

The computed total flow and steam discharge rate for wells $1,26,01,016$ and 24 during the 20-year exploitation period is shown in Fig. 8. Note during that period, the total flow rate decreased from 130.7 to $79.8 \mathrm{~kg} / \mathrm{s}$, and total stean rate from 71.1 to $38.8 \mathrm{~kg} / \mathrm{s}$. It means that at the end of exploitation these wells will only produce $19.4 \mathrm{MWe}$, if we assume a specific steam consumption of $2 \mathrm{~kg} / \mathrm{s}$ per MWe. Additional production from wells 013,014 and 037 may amount to $22.2 \mathrm{~kg} / \mathrm{s}$; that is, the total steam output for these wells will be $61 \mathrm{~kg} / \mathrm{s}$, or $30.5 \mathrm{MWe}$, at the end of the 20 years of exploitation.

The spatial distributions of computed temperatures, pressures and saturations in Layer 3 of the model, at the beginning and end of the 20 year period are shown in Fig. 9. The exploitation of the system results in decreases in temperatures $\left(5\right.$ to $10^{\circ} \mathrm{C}$ ) and pressures (up to 0.6-0.8 $\mathrm{MPa}$ ), and increases in steam saturation, especialiy in the vicinity of wells 1,01 and 24 and in the region above wells 013 and 037.

The effects of reinjection on the exploitation characteristics of the system are also shown in Figs. 8 and 9. In the model liquid with an enthalpy of $420 \mathrm{~kJ} / \mathrm{kg}$ was assumed to be injected into well 027 at a rate of $100 \mathrm{~kg} / \mathrm{s}$. Note the insignificant impact of reinjection on the total steam discharge of wells $1,01,24,26$ and 016 . On the other hand, the total flow rate increased up to $32 \%$ (Fig. 8). Some instability was observed in well 016 at the end of the 20 years of exploitation (it waters out after about 18 years).

Figure 9 also shows the spatial distribution of temperatures, pressures and enthalpies in the third layer of the model for the case with reinjection. After 20 years of exploitation, there is some decrease in steam saturation (10 to $15 \%$ ), increase in pressures (up to $0.2-0.6 \mathrm{MPa}$ ) and in tem- 
peratures. Some of the temperature increase in the case with reinjection may be due to the effect of heat recharge associated with the injection in well 027.

It is worthwhile to note that the total steam discharge of wells $1,01,24.26$ and 016 can be well represented by the formula:

$$
Q_{s}=36.1+36.7 e^{-0.011 t}
$$

where $Q_{s}$ is steam discharge, and $t$ is time in months. It seems that the same type of function for total steam discharge decline is appropriate to other exploitation scenarios for this field.

\section{CONCLUSIONS}

1. Based on the simulation studies carried out with the computer code TOUGH2, the 3-D natural-state distribution of temperatures, pressures and fluid phases, and the circulation characteristics of the high-temperature tluids obtained earlier (Kiryukhin et al., 1991; Kiryukhin, 1992) have been generally confirmed as appropriate initial and boundary conditions.

On the other hand, some unreasonable behavior seen in the simulations allowed to improve the natural-state model of the Dachny system, i.e.: (a) The upflow rate appears to be about $165 \mathrm{~kg} / \mathrm{s}$, instead of $228 \mathrm{~kg} / \mathrm{s}$ (Kiryukhin, 1992); (b) The permeability should be increased to $150 \mathrm{mD}$ at least in the area where wells 01,1 and 24 are located, and north of well 24; and (c) The steam output in the discharge area seems not to exceed $5-6 \mathrm{~kg} / \mathrm{s}$.

2. Subroutine DEBIT was implemented in TOUGH2 to model production wells, since it is necessary to have non-linear "well-reservoir" interactions for geothermal problems, with significant changes in produced enthalpy.

3. The fine-tuning of the permeability distribution in the model, including the implementation of a double-porosity model [with the help of the computer code GMINC (Pruess, 1983)] was based on matching the enthalpy-discharge characteristics of wells $016,26,01$, 1 and 24 measured at the end of the 1983-88 flow tests.

4. Two variants of 20 years of exploitation of the Dachny site were studied: (1) without reinjection, and (2) with reinjection. In both cases the total steam output of wells 1,01 , $24,26,016,014,013$ and 037 is sufficient to maintain the generation of 30 MWe during 20 years. However, the case with reinjection may affect the stability of the vapor-dominated reservoir (tapped by wells 016 and 26). 


\section{ACKNOWLEDGMENTS}

This study began at the Lawrence Berkeley Laboratory (LBL) in July-October 1991, where I had the opportunity to have access to a supercomputer and to the code TOUGH2, developed by Karsten Pruess. During my visit to LBL I had support from its staff scientists: K. Pruess, $M$. Lippmann, C. Doughty, G. Bodvarsson, E. Antunez, F. Hale, C. H. Lai, and K. Karasaki. I want to express my special gratitude to K. Pruess, who allowed me to use TOUGH2 at the Volcanology Institute, where this work was completed using a PC486 with a SVS extended Fortran77 compiler. I thank UNOCAL and the U.S. Department of Energy for their financial support that allowed my visit to LBL. I also appreciate the fruitful discussions with my colleagues S. Perveev (PGO "Sakhalingeologia"), D. Gusev, I. Delemen, M. Zhuravlev (Institute of Volcanology), K. H. Williamson (UNOCAL), M. Sorey, S. Ingebritsen (USGS), and P. Kruger (Stanford University). I especially would like to thank Judith Peterson (LBL) for producing the report.

\section{REFERENCES}

Allis, R.G., 1981. Changes in Heat Flow Associated With Exploitation of Wairakei Geothermal Field, New Zealand, N.Z.J. Geology and Geophysics, 24, 1-19.

Aunzo, Z.P., Bjornsson, G. and Bodvarsson, G.S., 1991. Wellbore Models GWELL, GWNACL, and HOLA: Users' Guide, Lawrence Berkeley Laboratory Report LBL-31428, Berkeley, Califormia, 102 p.

Benson, S.M. and Bodvarsson, G.S., 1986. Nonisothermal Effects During Injection and Falloff Tests, SPE Formation Evaluation, 1(1), 53-63.

Droznin V.A., 1980. Physical Model of the Volcanic Process, Nauka Publishers, Moscow, 92 p. (In Russian).

Grant, M.A., 1977. Permeability Reduction Factors at Wairakei, paper 77-HT-52, presented at the AICHE-ASME Heat Transfer Conference, Salt Lake City, Utah, August 1977.

Kiryukhin, A.V., 1992. High-Temperature Fluid Flows in the Dachny Field of the Mutnovsky Hydrothermal System, submitted to Geothermics.

Kiryukhin A.V. and Maltseva K.I., 1985. Two-phase Well Parameter Variation Analysis During Their Exploitation, Volcanology and Seismology Journal, N5, 41-47. (In Russian).

Kiryukhin A.V. and Piskacheva T.Y., 1985. Numerical Solution for System of Equation 'Wellgeothermal Reservoir', in Physical Processes in the Mining Industry, Leningrad Mining Institute, p. 33-39. (In Russian).

Kiryukhin A.V. and Sugrobov, V.M., 1987. Heat Transfer Models, in Hydrothermal Systems of Kamchatka, Nauka Publishers, Moscow, 149 p. (In Russian).

Kiryukhin, A.V., Delemen, I.F. and Gusev, D.N., 1991, High-Temperature Hydrothermai Reservoirs, Nauka Publishers, Moscow, 160 p. (In Russian). 
Pruess, K., 1983. GMINC - A Mesh Generator for Flow Simulations in Fractured Reservoirs, Lawrence Berkeley Laboratory Report LBL-15227, Berkeley, Califormia, 64 p.

Pruess, K., 1987. TOUGH Users Guide, Lawrence Berkeley Laboratory Report LBL-20700, Berkeley, Califomia, 78 p.

Pruess, K., 1991. TOUGH2 - A General Purpose Numerical Simulator for Multiphase Fluid and Heat Flow, Lawrence Berkeley Laboratory Report LBL-29400, Berkeley, Califomia, 102 p.

Vakin, E.A., Kirsanov, I.T. and Kiirsanova, T.P., 1976. Thermal Fields and Springs of the Mutnovsky Volcanic Region, in Hydrothermal Systems and Thermal Fields of Kamchatka, Vladivostok, 85-115 (In Russian).

Vakin, E.A., Pilipenko, G.F., and Sugrobov, V.M., 1986. General Features of the Mutnovsky Geothermal Field and Prognostic Estimate of the Resources, in Geothermal and Geochemical Studies of High-Temperature Geothermal Fields, Nauka Publishers, Moscow, 207 p. (In Russian).

Yanovsky F.A., 1989. Heat Conductivity of Volcanogenic Rocks in Kamchatka, Volcanology and Seismology Journal, N5, 77-84. (In Russian). 


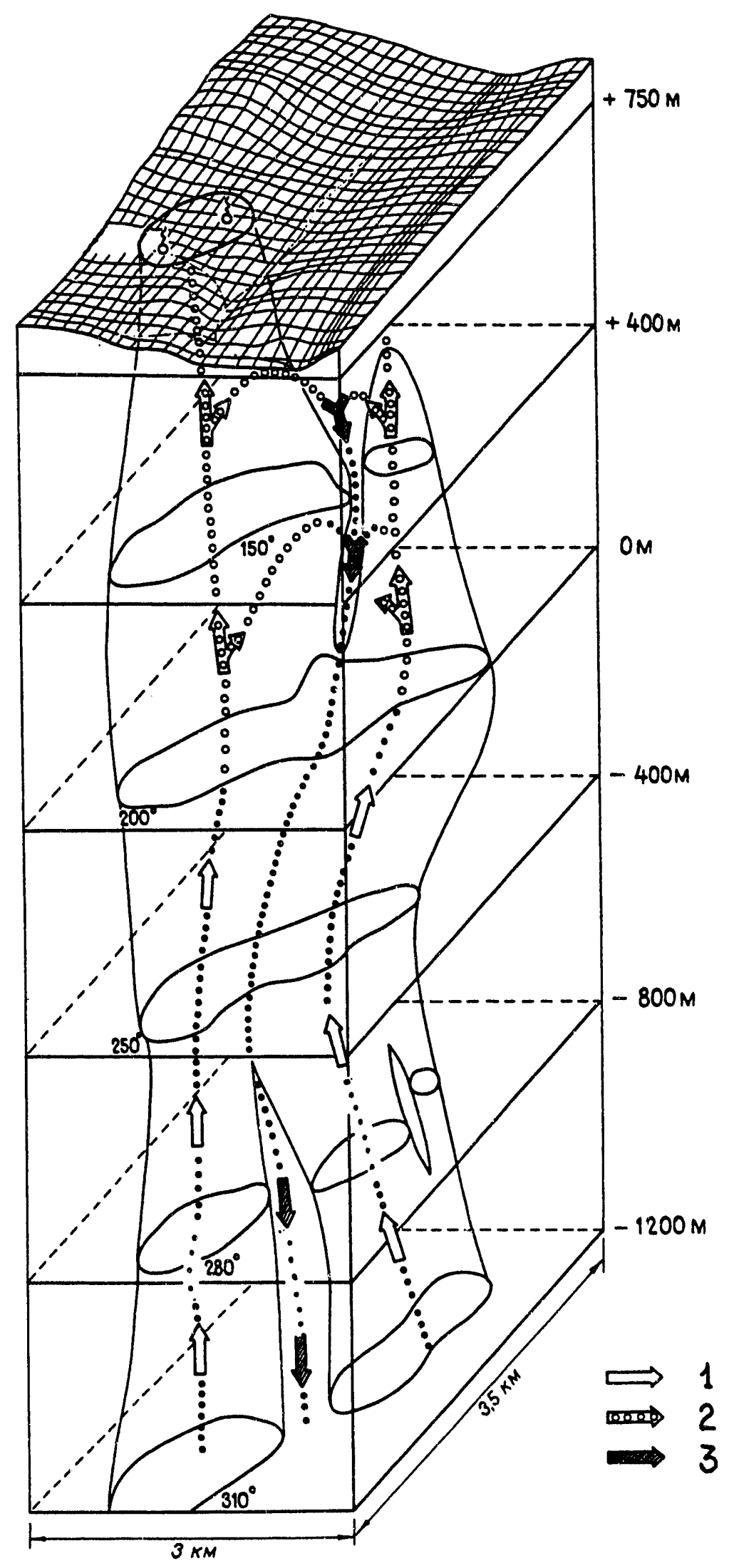

Fig. 1. High-temperature fluid flow model within Dachny site of the Mutnovsky geothermal field. 1-hot water upflows, 2-steam upflows, 3-hot water downflow. 

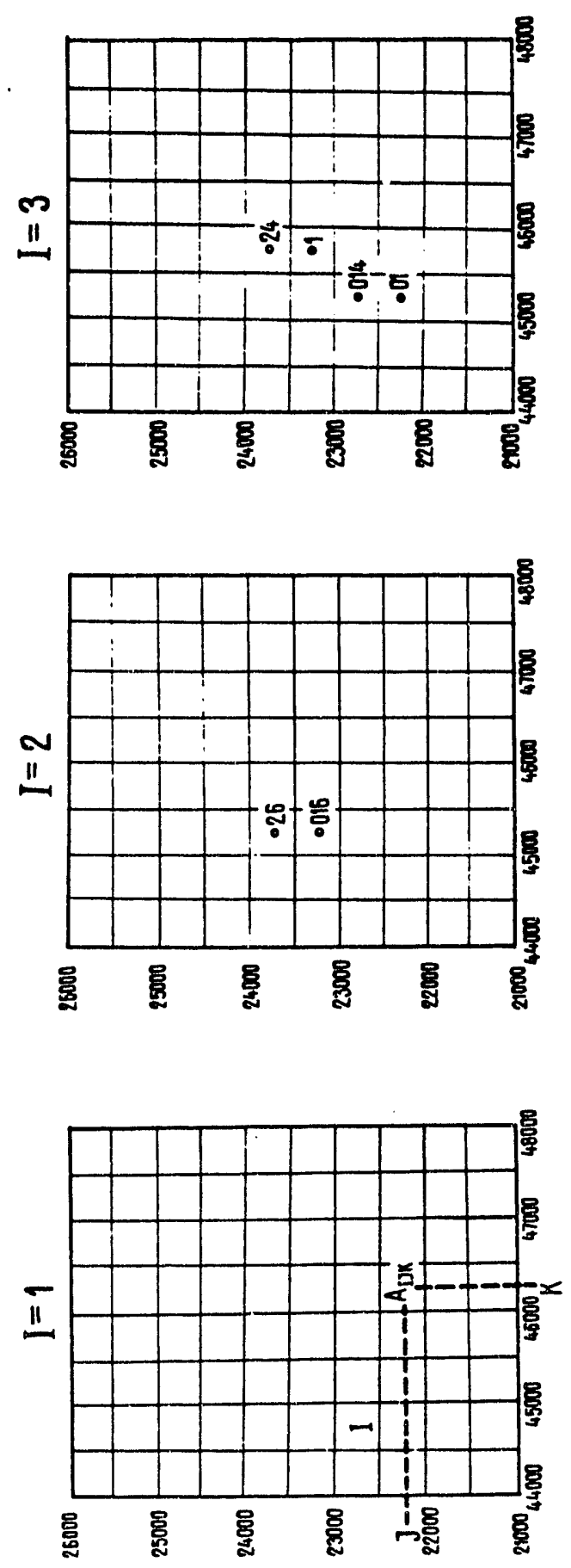

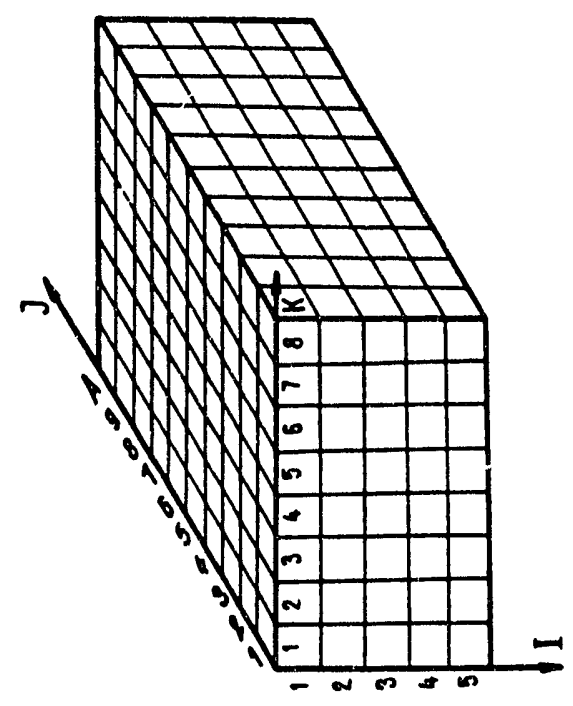

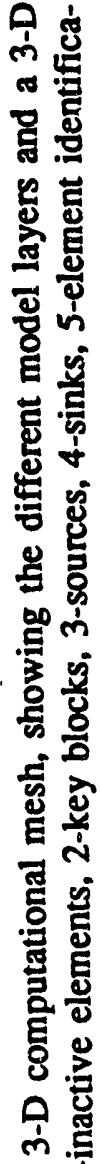

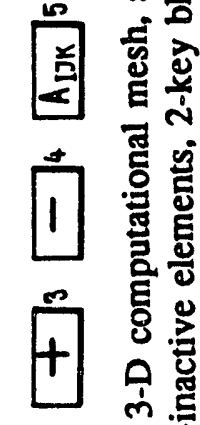

皮

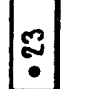

톨을

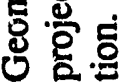

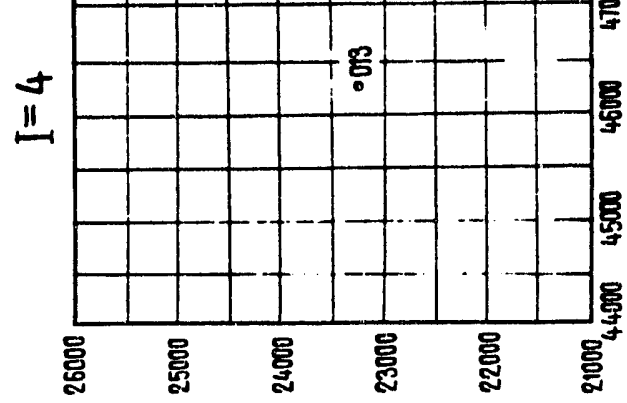

i 
$z=+250$
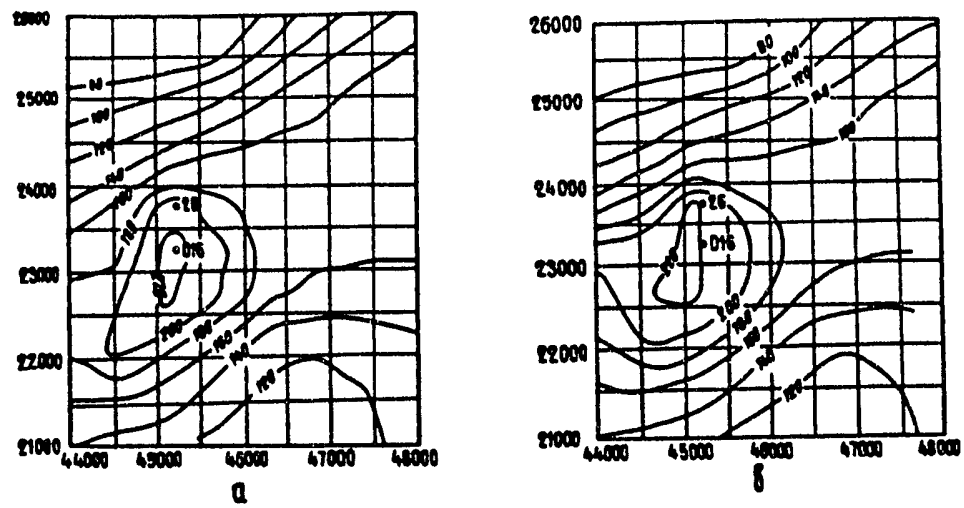

$Z=-250$
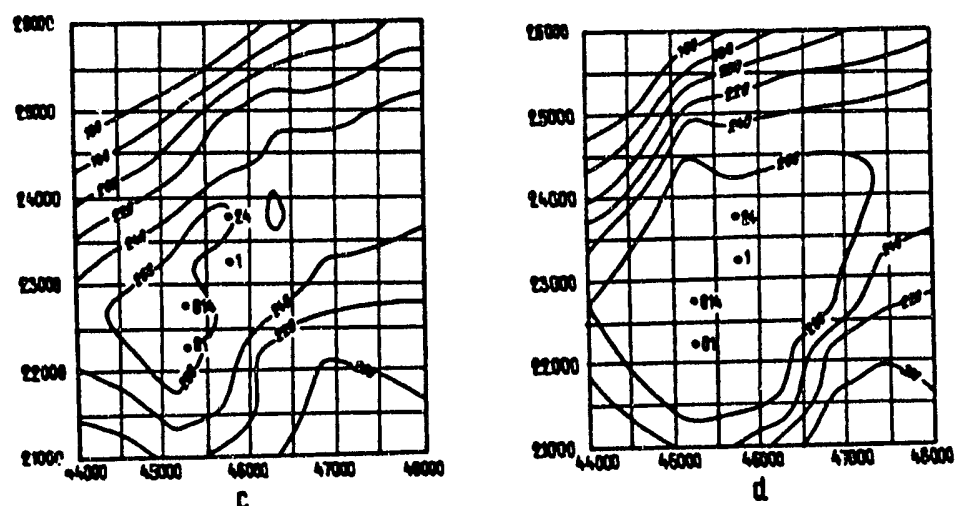

$z=-750$
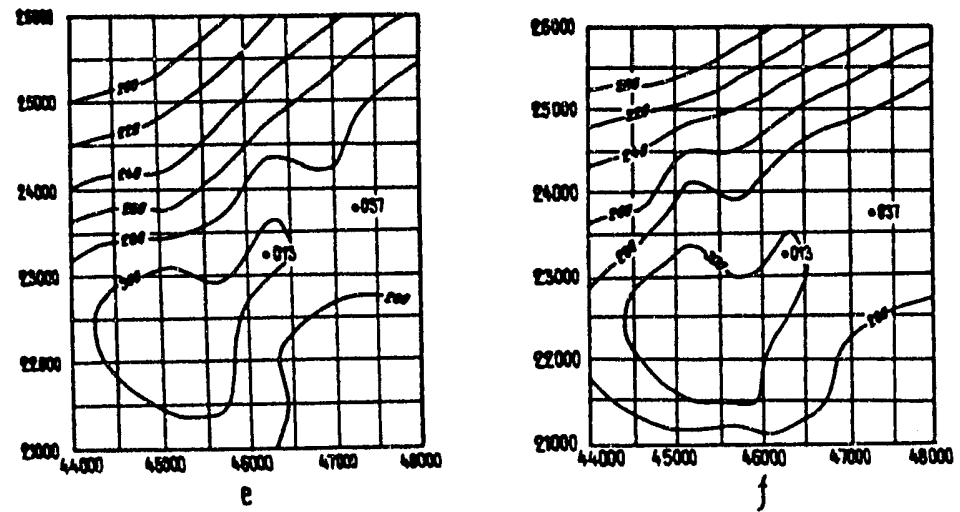

Fig. 3. Modeling the natural state of the Dachny site. Distribution at three different elevations (in masl) of input temperatures $(a, c, e)$ and quasi-stationary simulated temperatures at $t=365$ years $(b, d, f)$. Temperatures are given in ${ }^{\circ} C$. 

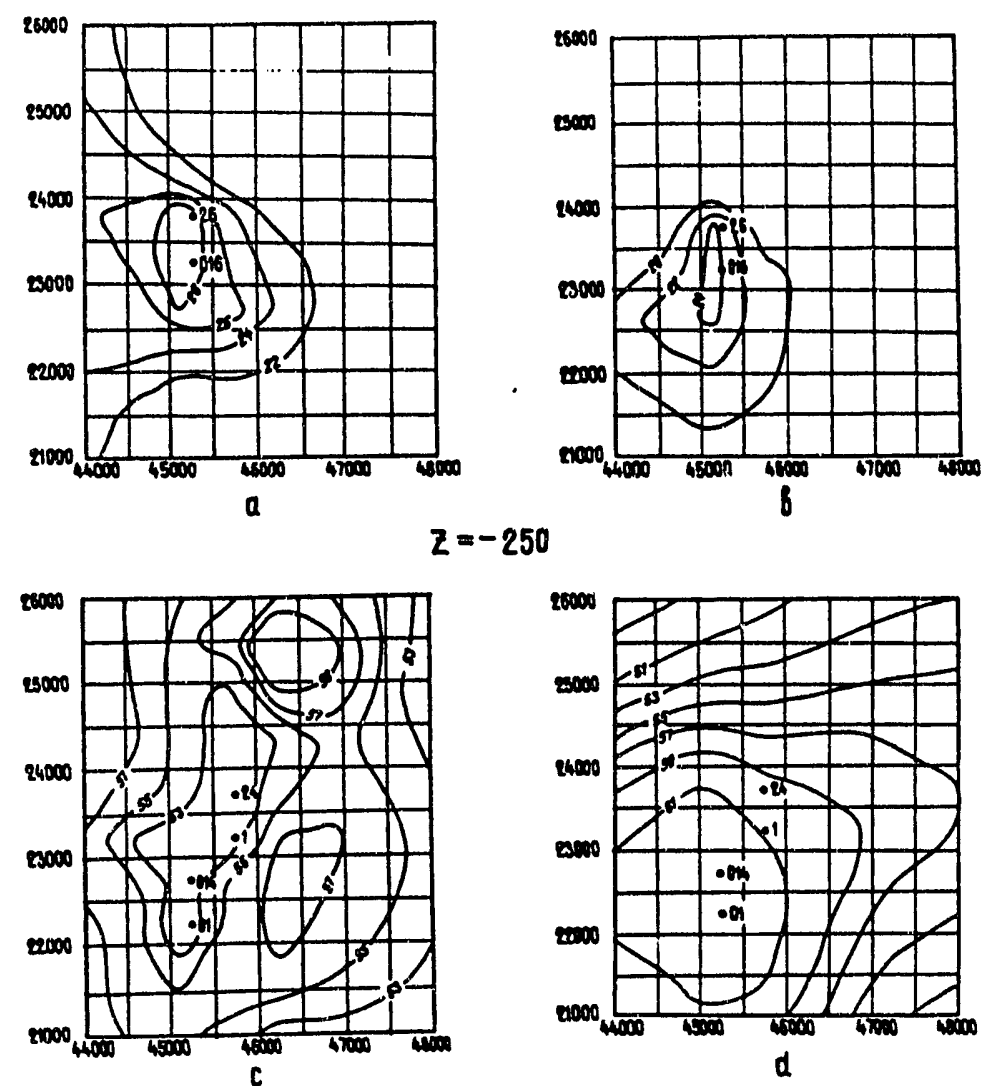

$z=-750$
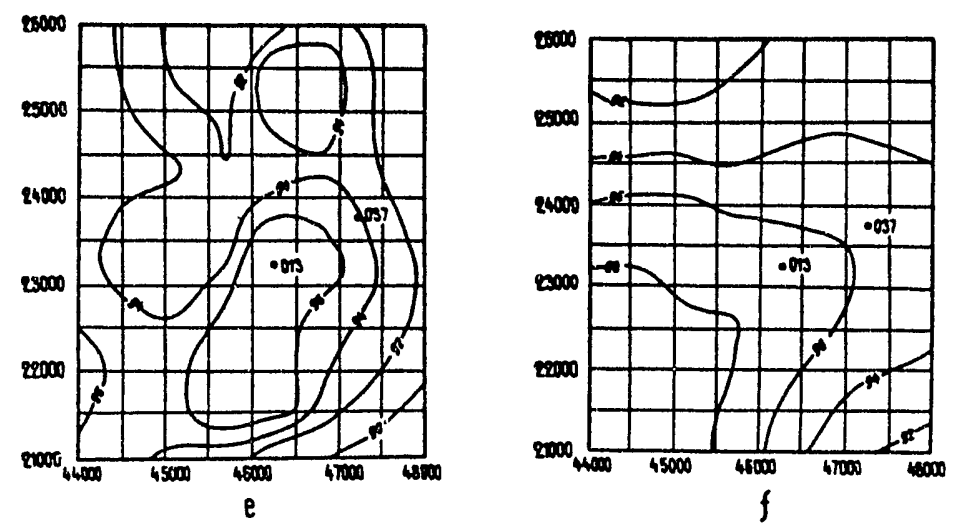

Fig. 4. Modeling the natural state of the Dachny site. Distribution at three different elevations (in masl) of input pressures $(a, c, e)$ and quasi-stationary simulated pressures at $t=365$ years (b, $d, f)$. Pressures are given in bars (0.1 MPa). 

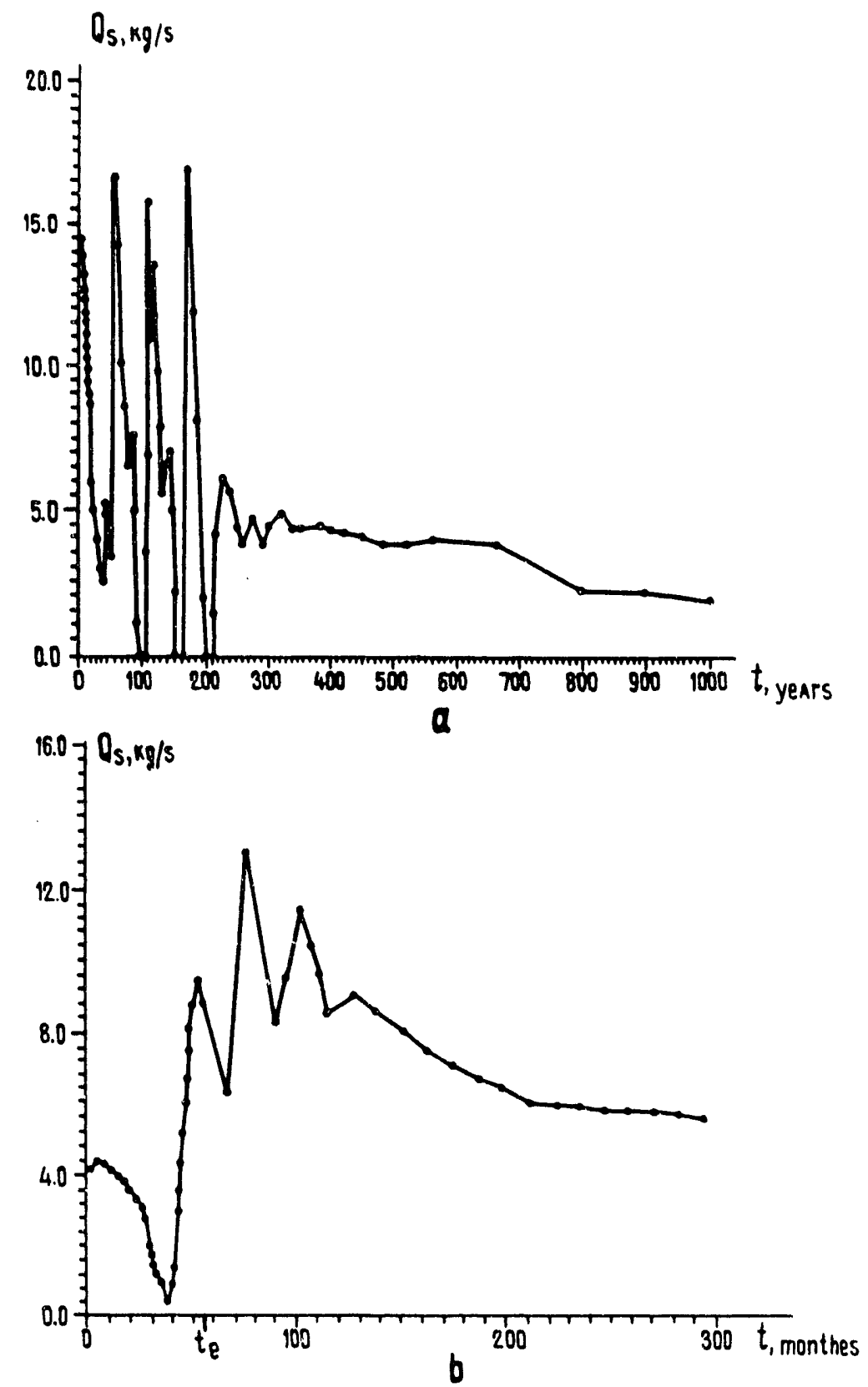

Fig. 5. Modeling the natural discharge of the Dachny site. Steam discharge from model elements A142/A242. (a) natural state, (b) exploitation period. 


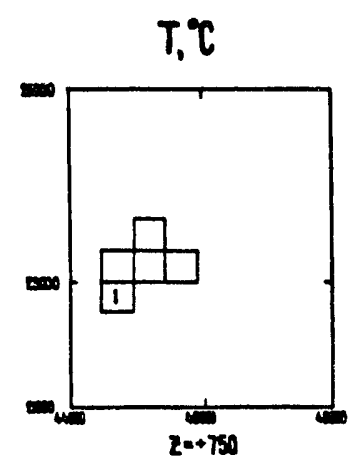

$\mathrm{P}, \mathrm{MPa}$
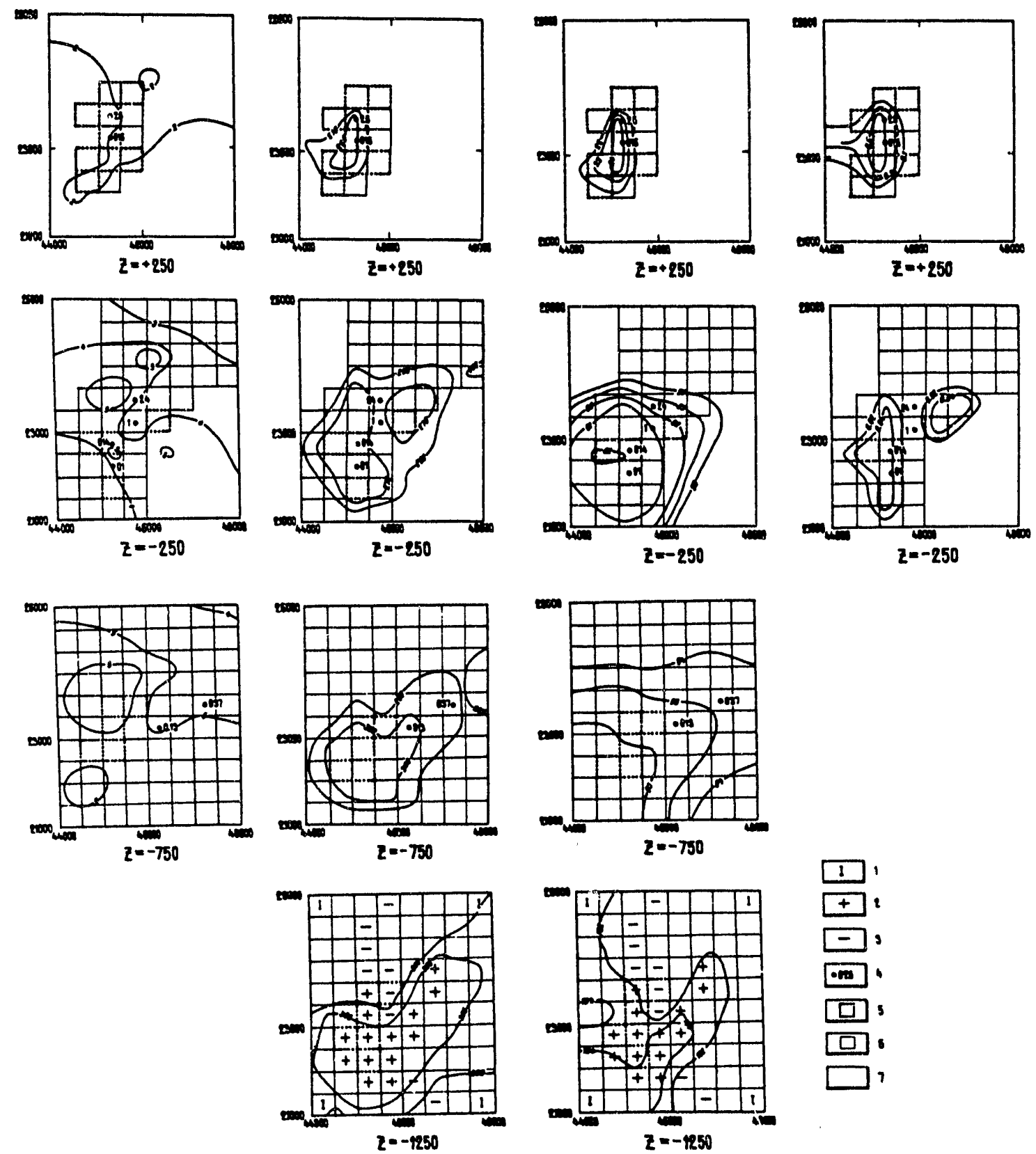

Fig. 6. Thermo-hydrodynamic model of the natural state of the Dachny site. Columns show the distribution of lithology, temperature, pressure, and steam saturation at different elevations (in masl). 1-inactive elements, 2-sources, 3-sinks, 4-well (key element) locations, 5permeabilities in the 30 to $150 \mathrm{mD}$ range, 6-permeabilities in the 1 to $30 \mathrm{mD}$ range, 7 . permeabilities less than $1 \mathrm{mD}$. Lithology symbols: $1-4=$ Unit (1), 4-5 = Unit (2), 5-6= Unit (3). 

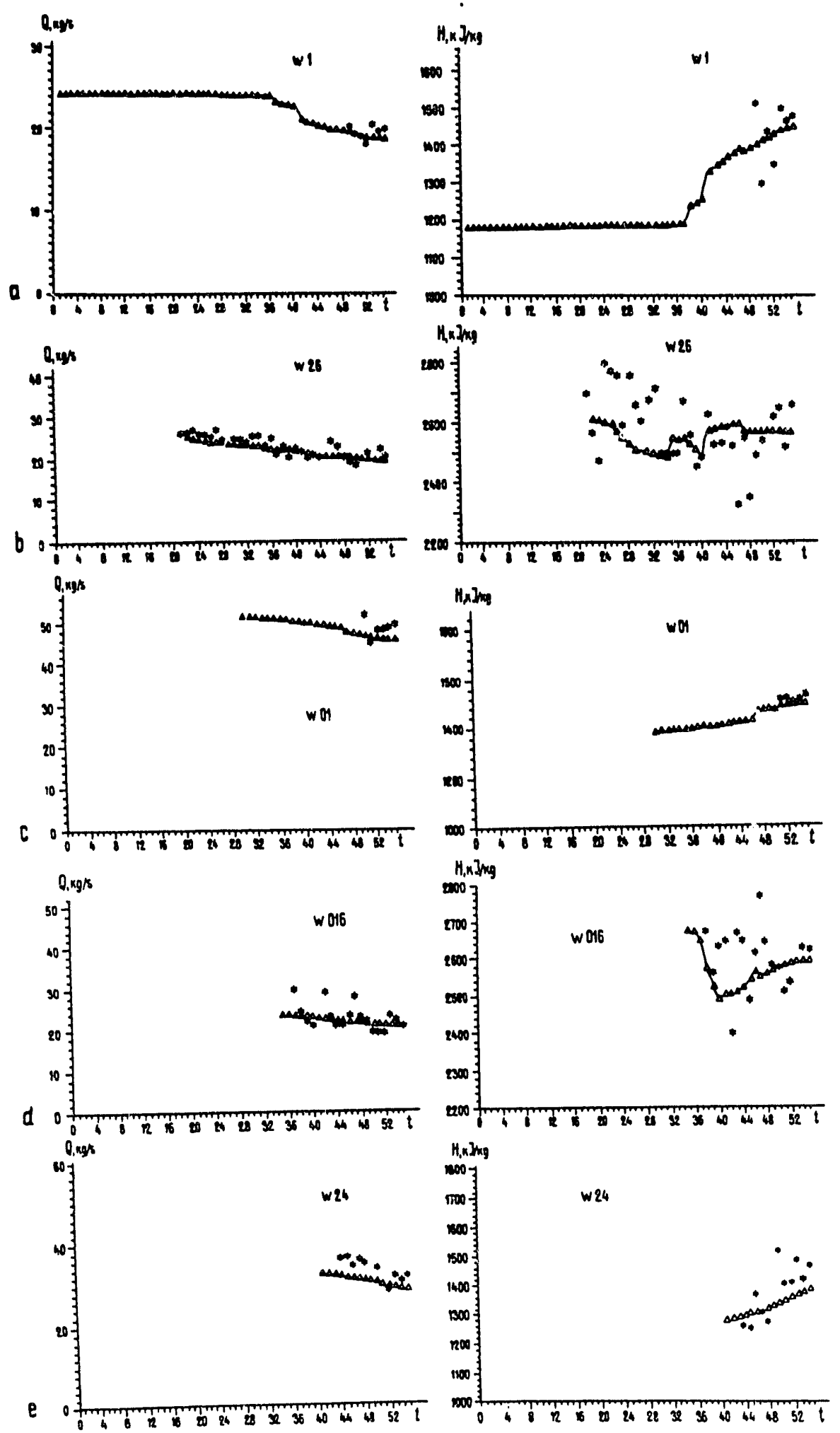

Fig. 7. Match of $1983-88$ flow tests. $\mathrm{Q}$ - flow rate $(\mathrm{kg} / \mathrm{s}), \mathrm{h}$ - enthalpy ( $\mathrm{kJ} / \mathrm{kg}$ ), $\mathrm{t}$ - time (months). Wells: 1 (a), 26 (b), 01 (c), 016 (d), 24 (e). 1 - observed, 2 - calculated. 


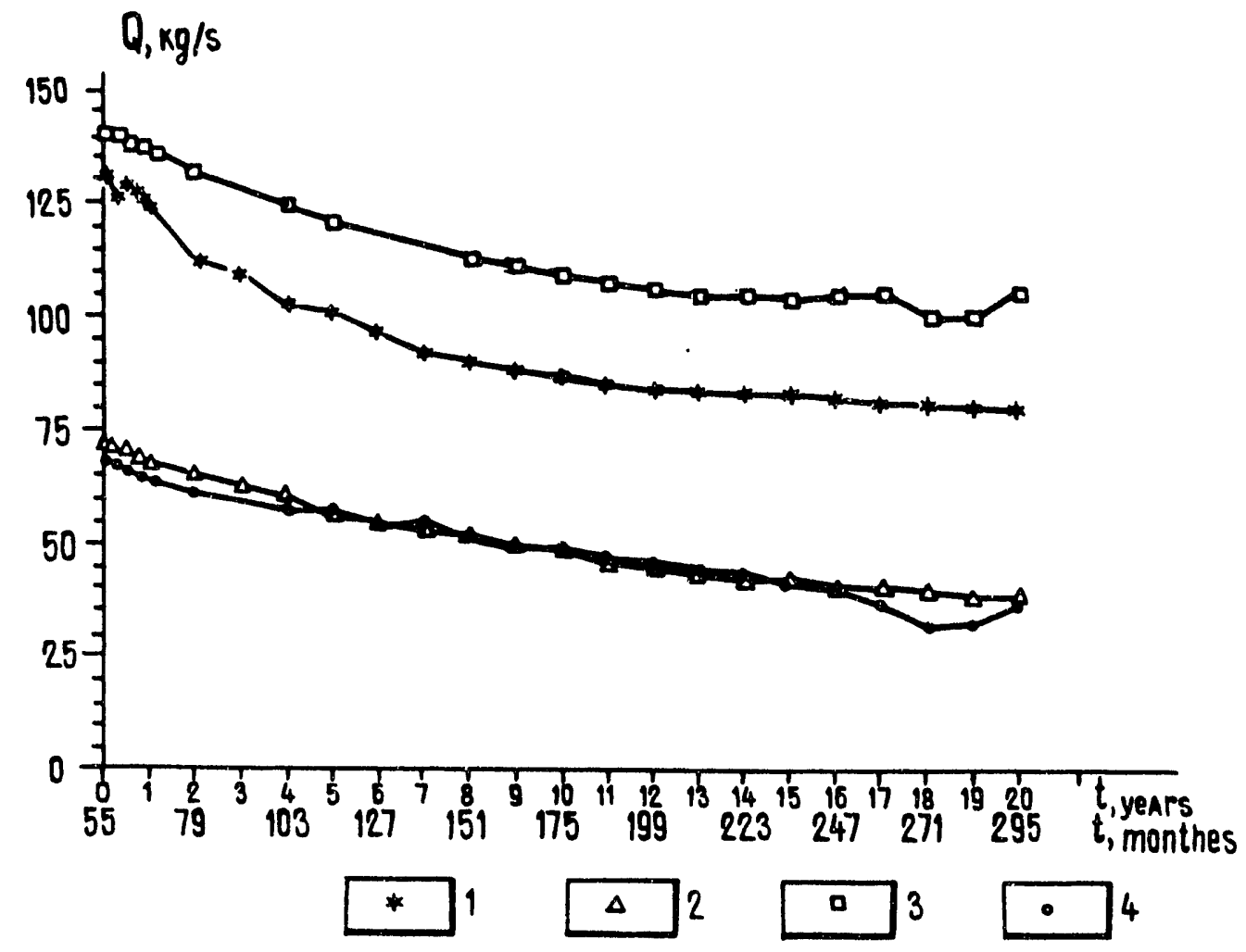

Fig. 8. Wells 1, 01, 24, 26 and 016. Computed total production for 20 year-exploitation period. 1 - total steam-water discharge, without reinjection

2 - total steam discharge, without reinjection

3 - total steam-water discharge, with reinjection

4 - total steam discharge, with reinjection. 
$\mathrm{T}_{0}^{\circ} \mathrm{C}$
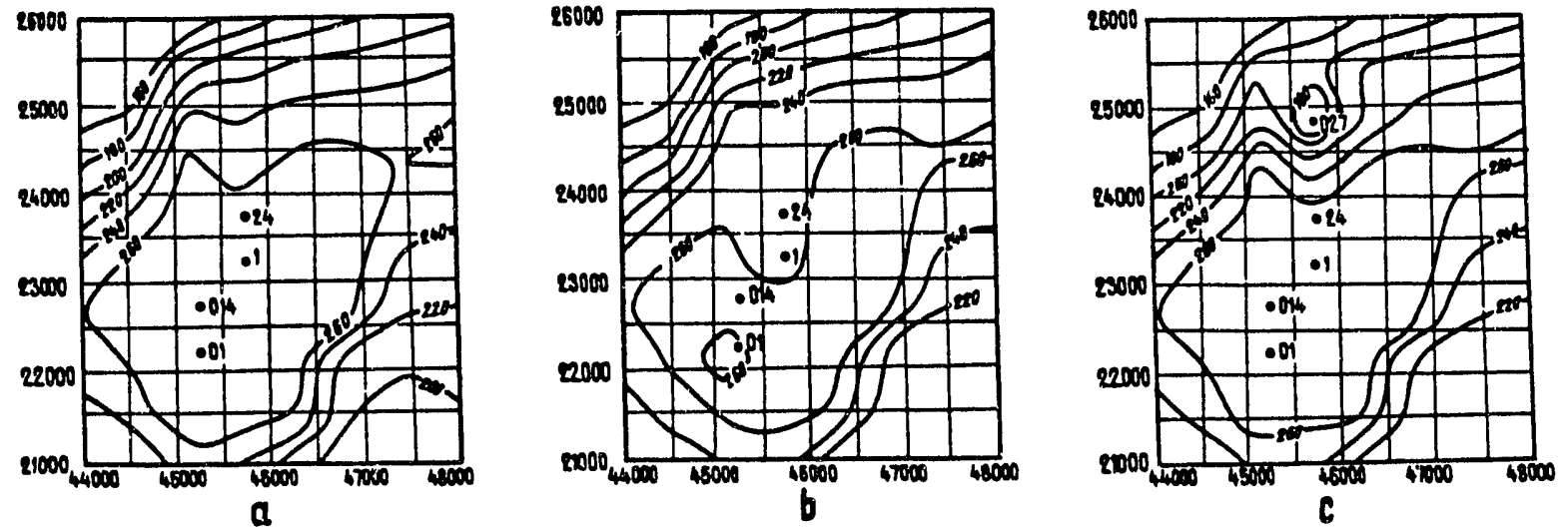

\section{$\mathrm{P}, 0,1 \mathrm{MPa}$}
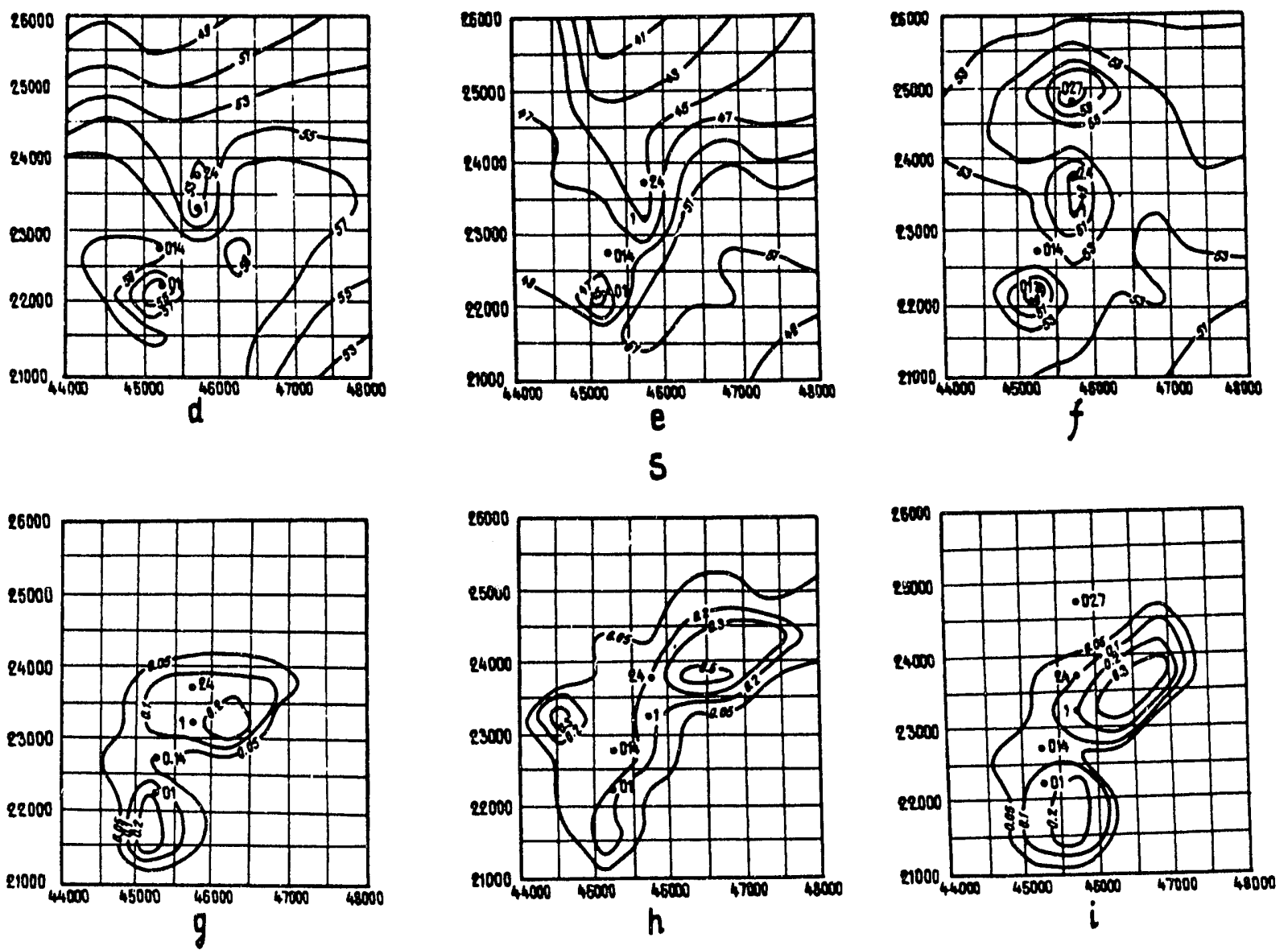

Fig. 9. Computed temperature, pressure and steam saturation distribution in Layer 3 of the model (at -250 masl). At the end of the 1983-88 flow-tests: a-temperature, d-pressure, gsaturation. At the end of 20 years of exploitation, without reinjection: b-temperature, epressure, h-saturation. At the end of 20 years of exploitation, with reinjection: c-temperature, f-pressure, i-saturation. 

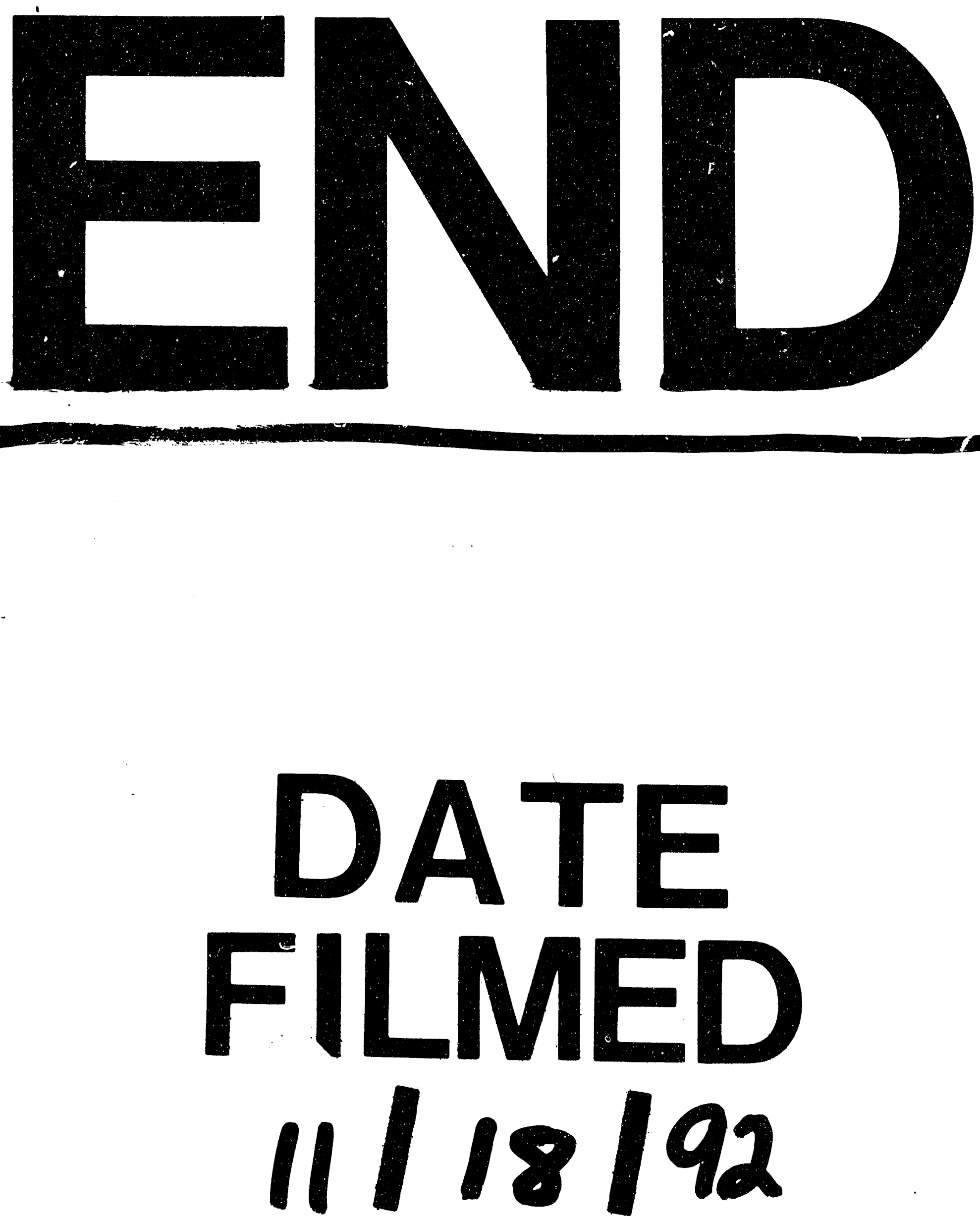
